\title{
HOW TO STOP SHARK FIN CONSUMPTION IN CHINA-LEGAL AND SOCIAL ANALYSIS
}

\author{
Song Wei*
}

\begin{abstract}
Although the Chinese consumption history of shark fin can be traced to 1,000 years ago, it was associated with nobilities, and had nothing to do with the ordinary people. In recent 100 years, shark fin starts to enter into daily life. The consumption areas in China are mainly concentrated in the coastal areas of Guangdong province. It is a bad catering culture criticized by many Chinese people since it appeared. It was almost extinct during Maoist Era. After the reform and opening-up, some Chinese people get rich quickly which led to extravagant consumption. Recent years, mainstream sounds of Chinese society opposed the consumption of shark fin, more and more media, restaurants, and local governments have refused to the consumption of shark fin. What Chinese society should do now is to have a comprehensive ban on shark fin in the area of legislation, law enforcement and administration of justice. A lot of work need to be done on it.
\end{abstract}

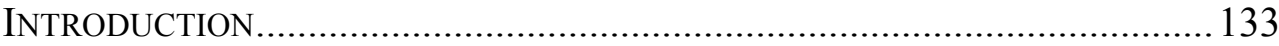

I. RELEVANT ISSUES ABOUT THE CONSUMPTION OF SHARK FIN...................134

A. $\quad$ The Tradition of China's Harmony with Nature ........................ 134

B. The Consumption of Shark Fin and Chinese Food Culture ..... 135

C. Shark Fin Consumption and Social Contradictions .................. 136

II. PROTECTION OUTSIDE THE LAW SYSTEM................................................136

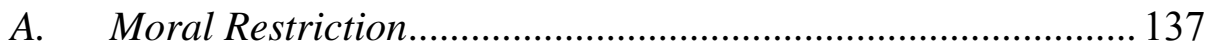

B. $\quad$ Pressure from the Voice of the Public ...................................... 137

C. The Discipline and Control of Government ...............................138

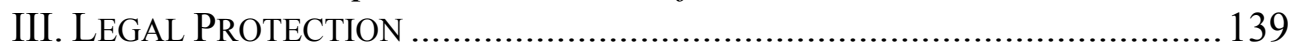

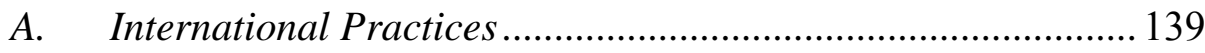

B. $\quad$ The Legal System in China ....................................................... 140

IV. Public InTEREST Litigation AND LegisLative Proposals ................ 144

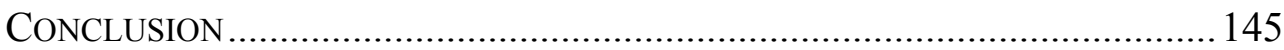

\section{INTRODUCTION}

A few years ago, shark fin consumption in mainland China, Hong Kong and Taiwan account for 95 percent of global consumption. China's wealthy families have been like to consume shark fin to indicate their wealth and status. As China's economy continues to develop, shark fin appears

\footnotetext{
* Professor and Director, Law Institute, Univ. of Science and Technology of China. Research fields: Animal Law, Science, Technology and Law, Intellectual Property Law.
} 
more frequently on restaurant menus. To meet the demand, as many as 73 million shark fins are cut off and transacted each year. Since shark fin is the most valuable portion of a shark, which is far more expensive than shark meat, many freshmen choose a cruel practice-cutting fin at sea. Sharks are drugged on the deck, cut off their fins while still alive and then thrown into the sea. Without fins, sharks will soon die. The growing demand for shark fin leads to 30 percent of shark species becoming endangered or nearthreatened. In the past 15 years, the number of hammerhead sharks, great white sharks and other sharks has reduced by $70 \%{ }^{1}$. According to the hunting speed, shark extinction is only a matter of time. When the strong demand drives the prosperity of shark fin trade, many people cannot help wondering: Is shark fin really as nutritious as people think it is? Why is it so sought after? How can we find a way to protect sharks?

\section{RELEVANT IsSUES ABOUT THE CONSUMPTION OF SHARK Fin}

Shark fin consumption is not only a behavior of buying, but closely related to the history, culture, social relations of a country. During the process of eliminating polarization, the campaign for or against shark fin consumption also reflects the fierce conflicts behind the curtain.

\section{A. The Tradition of China's Harmony with Nature}

Pursuit of the harmony with human and nature is the mainstream of the Chinese traditional culture for thousands of years. Chinese Confucian propose "nature and humanity", the personnel must comply with god's will, thus transformed from the nature's rule into the human's rule. Complying with them could get the peace and prosperity. Chinese Daoism proposes the nature of the Dao. Will the conception of "nature" to the height of the metaphysical. This so-called the nature of the Dao, "Dao" in accordance with the law of nature independent operation, and the universe has the operation rule which is beyond the subjective will. Laozi (founder of Daoism) believes that, breach the laws of nature, humanity must conform to nature. Chinese Buddhist said that, "Buddha nature" is the primitive of all things. The vastly different of the universe are different forms of "Buddha nature", its essence is still the Buddha's unity. The Buddha's unity, which means that, everyone is equal, everything has the right to live.

China already has its own environmental protection laws. Four thousand years ago in Xia dynasty, people are not allowed to cut down the

\footnotetext{
${ }^{1}$ See Refusing to Eat Shak Fins Ongoing, Think TANK OF SCIEnCE \& TeChnOlogy 12 (2012).
} 
trees in spring, and no fishing, no killing animal cubs and no collecting eggs in summer; About three thousand years ago, in Zhou dynasty, according to the seasonal climate, there exist strict rules on the time of hunting, birding, fishing, cutting down trees and burning; Two thousand years ago, in the Qin dynasty, the government listed several rules, for example, banning the collection of sprouting plants during spring, forbidding the capture of young beast and the using poison to kill turtle. All of Chinese feudal dynasties have clear regulations on environmental protection.

\section{B. The Consumption of Shark Fin and Chinese Food Culture}

(1) The history of eating shark fin. The history of eating shark fin in China can be traced to 1,000 years ago, some Chinese believed that, eating shark fin will reinforce Qi, appetizing, moistening skin. In the Song Dynasty, Shark fin started to become a valuable food, and in the Ming Dynasty, people began to eat Shark fin, mainly used in the imperial cuisine. During the reign of Emperor Qianlong of Qing Dynasty, eating shark fin become popular among senior officials, in the late Qing Dynasty, Shark fin were popular among businessmen, and also a way to show off their wealth. After the founding of new China, the consumption of shark fin gradually disappeared because of the implement of the thrift policy.

(2) Eating shark fin is not a traditional Chinese catering culture. The regional distribution of eating shark fin is not widely in China. The majority of Chinese people have never eaten, the consumption of shark fin concentrated in minority areas and a few people, but the harm is very serious.

(3) The side-effects of eating shark fin. Sharks contain a high concentration of $\beta$ - Methylamino -L-Alanine (BMAA), it's a kind of neurotoxin about cerebral degeneration and Lou Gehrig's disease, easily leading to Alzheimer's disease, progressive muscle weakness and even paralysis. Liu Qingchun, Deputy Director Nutrition nutritionist of General Hospital of Armed Police Forces in China, thinks this neurotoxin can cause nervous system damage, leading to muscle atrophy, affecting the digestive system, respiratory system and so on. Researches have shown that, sharks are on the top of the ocean food chain, as a result of the accumulation of toxins, mercury or other heavy metals components contained by shark fin is much higher than other fish. High levels can damage the central nervous system and kidneys, causing fetal malformations, producing blood diseases 
and other hazards. ${ }^{2}$

\section{Shark Fin Consumption and Social Contradictions}

In China, the consumption of shark fin is as a symbol of wealth and status, Shark fin was used for Business fete, birthday, wedding and other activities. Shark fin was used as a luxury in itself embodies the disparities between the rich and poor and class distinction. In China's today of eliminating the polarization, the consumption of shark fin reflects the gap between the rich and poor. The slogan of refusing to eat shark fin to some extent shows that, the general public's discontent on the power and wealth of owner's personality and behavioral. Against the consumption shark fin in China is not only an environmental protection activity, but also embodies the behind on behalf of the multiple demands - the fair distribution of wealth, the constraint of public power, social harmony etc., and its influence is rising.

Since the price of shark fin is very high, this attracts fishermen from around the world to vying to kill sharks in the sea, with an average of 26 to 73 million sharks were killed each year, millions of sharks died, the number of many populations were reduced by $90 \%$ than the past; while shark's peculiar habits, such as long gestation, less production, slow growth, complex life cycle, etc., determines their populations cannot recover in the short term, which has a significant negative impact on the marine balance.

At present, the catches of sharks are about more than 2 times than the reproduction. Chinese famous ichthyologist $\mathrm{Wu}$ Hanlin said: "Now the resources of sharks are fewer and fewer, if not protected, maybe someday we will not see the shark." A survey conducted by the IUCN Species Survival Commission Shark expert group shows that, in the open sea, one third of sharks are endangered, and almost are unprotected. In the endangered species list of the IUCN, a total of 126 species of sharks were listed as critically endangered, endangered or vulnerable category.

\section{ProteCtion OUTSIDE THE LAW SySTEM}

Except legal method, it is critical to use moral restriction and pressure from the public voice to help protect sharks, especially in the fight against the consumption of shark fins. In China, it includes a unique means of government discipline and control.

\footnotetext{
${ }^{2}$ See Eating Shark Fins May Cause Alzheimer's, (Feb. 26, 2012). Available at http://news.xinhuanet.com/food/2012-02/26/c_122754901.htm.
} 


\section{A. Moral Restriction}

About the protection of shark and the refusal to eat shark fins, morality is the fundamental power. The function of morality is one kind of restriction, compelling every single man to follow his inner ideas and enforce people to condense the self-decision's room and procedure. The final destination of the virtual activity from public promotion and public organization resides that, it raises every man's inner perception and it also puts light upon the cruelty of killing sharks, the harm stemming from sharks' extinction to human development and what the side effects single man's uncivil deeds bring to society and others. When we give expectation to personal deeds, there also exists moral risk. The reason for that is that moral restriction is not that stable.

\section{B. Pressure from the Voice of the Public}

Pressure of public voice which is a kind of exterior restriction bases on the public's consciousness and the judgments upon the protection of common interests. It mainly has following aspects:

In 2006, the Chinese branch of world wild aid invited Yao Ming to make a non-benefit ad and act as the shark ambassador. Moreover, to making the protecting ads, the inviting list includes Lining, Guo Jingjing and so on.

In April, 2009, the Chinese entrepreneur club cooperate with the Chinese office of wild aid Liu Chuanzhi, Wang Shi and Ma Yun called for hundreds of entrepreneurs to start from themselves, "protect sharks, refuse to eat shark fin," with actions affecting the wealthy group who eat shark's fin.

In August of 2011, the chairman of Qiao Jiangnan, Wang Xiaofei initiated action against eating shark fin on his micro blog, and said that, since October, Qiao Jiangnan have canceled all the dishes about shark's fin on its new menu, getting such support of stars as Shu qi, Wang Fei and so on.

On November 21, 2011, Hong Kong peninsula hotel (Hong Kong's first hotel halting the sale of shark fin in its restaurant shop) announced that, from January 1, 2012, it would suspend the shark's fin dishes. Today, according to the "first financial daily" reports, there are already 112 companies promising to stop eating shark fin.

On January 17, 2012, the Shangrila hotel's restaurants and banquet and cease the sale of shark fin food completely.

In 2012, during the sessions of the CPPCC national committee, the 
executive of new Oriental: Mr. Yu said on his Weibo that, he agrees with the chairman of Ya Chang company Wanjie, who is also a representative of the CPPCC national committee, with his own signature on the refusal to eat shark. $^{3}$

On August 24, 2013, during Yabuli entrepreneur's summit Wang Shi called for entrepreneurs to eat less shark's fin, drawing a lot of applauses. ${ }^{4}$

In October of 2013, WildAid and Hunan TV launched a large online charity event called "I'm finished with fins". In almost one mouth, a total of over 36 million people participated on Weibo, making a commitment not to eat shark fins. It covered a population of 240 million, 50 million online, and participators online up to 333 thousand. $^{5}$

In July of 2015, Departments of Ocean and Fisheries of Liaoning Province and Fushun Royal Marine Park organized a joint protection event named "efusing to eat shark fin for environmental protection". 6

On August 20, 2015, an art circuit of shark protection holds in National Museum, which aims to focusing on saving sharks and preserving the ocean. ${ }^{7}$

Media reveals on shark fin consumption and criticizes all kinds of ugly phenomena, triggering a widespread discussion about the cruel way of producing shark's fin, the problems of falsification in shark fin market, etc.. At the present stage, China is trying its best to stop unhealthy practices sharply. In this context, the media also intends to focus on governmental spending. Once found, the phenomenon which has the same consumption as shark fin will be exposed. Such consumption will be regarded as typical case and alerted, which has a strong influence and deterrence.

\section{The Discipline and Control of Government}

In April of 2011, before Chinese IT summit, Shenzhen government told the organizing committee that everyone just came, and shark fin dishes would not appear in the party.

In March 2011, the 11th Chinese senior meeting, Ding Liguo, Guo

\footnotetext{
${ }^{3}$ See The "Warfare" of Shark Fin, (Sep. 03, 2012). Available at http://www.ceweekly.cn/2012/0903/26128.shtml.

${ }^{4}$ See Wang Shi: Eating Shark Fin is a Sin, (Aug. 24, 2013). Available at http://finance.sina.com.cn/hy/20130824/094916551290.shtml.

${ }^{5}$ See Refusing to Eat Shark Fin for Environmental Protection, (Nov. 14, 2013). Available at http://news.xinhuanet.com/politics/2013-10/14/c_125533387.htm.

${ }^{6}$ See Protecting Sharks Ongoing, (July 27, 2015). Available at http://news.xinhuanet.com/politics/2013-10/14/c_125533387.htm.

${ }^{7}$ See Art Circuit of Shark Protection Hold in National Museum, (Aug. 21, 2015). Available at http://fashion.qq.com/a/20150821/050377.htm.
} 
Guangchang from people's congress together with over thirty delegates put forward the calling for a ban on official business and official banquets on shark fin consumption. By means of legislation, China government will make a ban on the trade of shark fins, keeping the Marine environmental balance.

In June 2012, the Chinese authorities said that, official reception shall not be eating shark fin. At the end of 2012, the central government issued "eight disciplines" and "six ban", for "practicing frugality" and "prohibiting excessive reception". 8

On December 8, the Chinese government announced the new vision of the 38 bans, one of which is requiring supplying home dishes instead of shark fin, bird nest and other dishes made of wild animals at official banquets. This ban has been highly praised by international environmentalists who believe it would create a precedent for protecting endangered animals. ${ }^{9}$

Remarkably, the discipline and control of Chinese government is tougher and more effective than the law and policy. Such constraints have a certain deterrent effect, to some extent, the excessive consumption and banquet at public expenses are being curbed, but there are also some limitations: (1) The object focus on civil servants, so constraint range is relatively narrow; (2) A variety of upscale club are trying to hide themselves; (3) The lower cost of breaking rules, mandatory punishment does not meet practical needs. The punishment is not enough on the breadth and depth.

\section{LEGAL PROTECTION}

Due to the moral constraint, the pressure of public opinion, and lack of discipline control, legal protection which is essential really have long enforced. Law is the last barrier to adjust social relations, the cry for adjust social relations should be brought into the adjustment range. Global Shark resources failure raises concern from all over the world, shark protection in need of legal force.

\section{A. International Practices}

In 1973, the Convention on International Trade in Endangered Species of Wild Fauna and Flora (CITES) lies in the spirit control rather than

\footnotetext{
${ }^{8}$ See SHARK Sin, BAidu EncyClopedia. Available at http://baike.baidu.com/link?url=ndNREU_o29ULJbJu1 omPDkyaUbes4Mh0xGQEn6NSNILU_poqE nczJWBVva7hJunzIRv8Wszp9ORHyvYK̄qz_kVTJrhp61F_FSFH1U3VrlHie.

${ }^{9}$ See Environmentalists Highly Praise Official Bans, (Dec. 10, 2013). Available at http://world.huanqiu.com/exclusive/2013-12/4645362.html.
} 
completely ban on the international trade of wild species, use the species classification and license ways to achieve the sustainable wild species in the market, make sure all species entering the international trade is not in danger, but driven by illegal trafficking is still rampant.

In 1999, FAO drew up the International Action Plan on Protection and Management of Sharks, encourage members regularly assess the number of sharks, carry out shark maintenance and management, to ensure the sustainable utilization of the sharks.

In 2003, The United Nations general assembly passed a resolution, which requires member states to ban shark fin trade. But these are only file advocacy, no specific sanctions, there is a big difference between each country whether to perform.

In terms of refuse to eat shark fin, each countries and regions have different understanding of this, the law also have different attitude toward it. On the protection of sharks, many actions can learn from each other:

(1) Ban on trading. In Hawaii, California and New York in the United States, Canada, Brandt, Oakville city, Toronto, Chinese Taiwan area and so on, by the laws of sales of any shark fin should be banned.

(2) Ban on shark fishing. Such as absolutely no shark fishing in Costa Rica, the republic of the Congo, Brazil, Canada, Myanmar and Oman, also include parts of the United States and Australia, etc..

(3) List the sharks as special protected animals. Such as the British government sought to Basking Shark in the second class protected animals and banned the shark products trading; the Australian government proposed to the Great White Shark first class protected animal in the world list, and banned the great white shark products trading all over the world. Tiger sharks are now in the United States, Honduras, India, Thailand, Malaysia, the Maldives and many other countries are protected, the breed will also by strong calls for the first kind of protected species list.

(4) Establish a shark sanctuary. U.S.-based animal rights group "pew charitable trusts" shark expert Angelo Villa Quiroga said in September, 2013, he will meeting with Pacific island leaders during the Pacific Islands Forum, discuss to extend some shark conservation areas. The Marshall Islands has banned shark fishing since 2011, and in the shark protection zone was found two foreign ships with shark's fin, fined more than 100 thousand dollars.

\section{B. The Legal System in China}

In China, environment-related laws are mainly the Constitution, 
Environmental Protection Law, Fisheries Law, Wild Animal Protection Law and other related and complementary laws and regulations.

\section{The Provisions in the Constitution}

The provisions in the Constitution are mainly in the General Principle part. Article $9^{10}$ : "The state ensures the rational use of natural resources and protects rare animals and plants. Appropriation or damaging of natural resources by any organization or individual by whatever means is prohibited". Article 12 11 : "Socialist public property is inviolable. The state protects socialist public property. Appropriation or damaging of state or collective property by any organization or individual by whatever means is prohibited." Article $26^{12}$ : "The state protects and improves the environment in which people live and the ecological environment. It prevents and controls pollution and other public hazards." All the above provisions reflect that, the state on one hand protects wild animal and improves the ecological environment from a positive way, on the other hand, it cracks down on the start point and objective of illegal and criminal activities.

\section{The Provisions in Environmental Protection Law}

Environmental Protection Law of China mainly covers two aspects"protection and improvement of living environment and ecological environment", and "prevention and control of pollution and other public hazards". The Law implements government supervision and management responsibilities on environment problems, and clarifies legal responsibilities of government agencies, other institutions and individuals. According to the provision of Article $29^{13}$, "The people's governments at various levels shall take measures to protect regions representing various types of natural ecological systems, regions with a natural distribution of rare and endangered wild animals and plants .... Damage to the above shall be strictly forbidden." In Article $46^{14}$, it stipulates: "If an international treaty regarding environmental protection concluded or acceded to by the People's Republic of China contains provisions differing from those contained in the laws of the People's Republic of China, the provisions of the international treaty shall apply, unless the provisions are ones on which the People's

\footnotetext{
${ }^{10}$ See The Constitution of China, Article 9, Paragraph 2.

${ }^{11}$ See The Constitution of China, Article 12.

${ }^{12}$ See The Constitution of China, Article 26.

${ }^{13}$ See Environmental Protection Law of China, Article 29.

${ }^{14}$ See Environmental Protection Law of China, Article 46.
} 
Republic of China has announced reservations." The clauses in Environmental Protection Law are specific provisions of Article 9 of Constitutional Law.

\section{The Provisions in Fisheries Law}

The Purpose of the Law is "enhancing the protection, increase, development and reasonable utilization of fishery resources, developing artificial cultivation, protecting fishery workers' lawful rights and interests and boosting fishery production." In Chapter 3 "Fishing", the law confirms the principle - "the amount of Fishing should be less than the increasing amount of the fishery resources" 15 , and the rule of "Fishing Licenses" to prevent overfishing. There are special provisions in Chapter 4 "Increase and protection of fishery resources": "the State maintains special protection of the rare and endangered aquatic wild animals such as white-flag dolphin to prevent them from extinction. Killing and injuring of important aquatic wild animals protected by the State is prohibited. Where it is necessary to catch such animals for purposes of scientific research, taming and propagation, exhibition or for other special purposes, the matter shall be dealt with in accordance with the provisions of the Law of the People's Republic of China on the Protection of Wildlife." 16 The above provisions are the most direct protection of wild animal resources from the angle of fishing control. But it also permits specific fishing for purposes of "scientific research, taming and propagation, exhibition or for other special purposes", which may provide a "legal cloak" for illegal economic interests, and make it more difficult to protect wildlife.

a. The provisions in Law of the People's Republic of China on the Protection of Wildlife and other related regulations

Law of the People's Republic of China on the Protection of Wildlife aims to protect wildlife and it stresses the management responsibilities of the government. The related regulations include Regulations for the implementation of the wild animal protection law, Regulations of protection of terrestrial wild animals, Regulations for the implementation of the protection of aquatic wild animal. However, all these regulations only protect terrestrial or aquatic wild animals that are included on the "lists of wildlife under special state protection". There is a laissez-faire attitude toward protection of wild animals outside the "list" and shark is not on the list.

\footnotetext{
${ }^{15}$ See Fisheries Law of China, Chapter 3.

${ }^{16}$ See Fisheries Law of China, Chapter 4.
} 
b. Other supplementary regulations

Other supplementary regulations comprise Education Law, Higher Education Law, Food Safety Law, Tort Law and so on. Education Law series emphasize educates' all-round development of morality, intelligence and body. Education on ecological environment protection is one important aspect. The Ministry of Education has formally incorporated the "animal welfare and animal protection" into the main courses in colleges and universities, which means that, "Animal Welfare" will be regarded as a major compulsory course of veterinarian-related major in universities in the future. ${ }^{17}$ Tort Law series emphasize legal liability for infringement of wild animal.

Although there is no specific laws and regulations formulated for the purpose of shark protection in China, shark protection is still regulated by current domestic laws and international treaties that are effective in China. Currently, three standards are used to determine whether an animal belongs to endangered species or not. They are "IUCN Red List of Endangered Species", "CITES Appendix" and "Lists of Wildlife under Special State Protection" in China. Among them, "CITES Appendix" and "Lists of Wildlife under Special State Protection" are mandatory laws and regulations, which belongs to international law and domestic law, respectively.

An international treaty should be abided by if China has acceded to it. Although shark as one kind of Chondrichthyes has not been included in the Chinese "national key protected wild animal list", some kinds are still encompassed in the Chinese "national key protected aquatic wild animal list" and some local "wildlife protection lists". ${ }^{18}$ For example, whale shark is regarded as wildlife under special protection in Guangdong Province. Three species of Sharks are listed in the CITES Appendix II, which are whale shark, basking shark and great white shark.

Some other shark species included in the "IUCN Red List of endangered species" are also distributed in China. Five species of ocean sharks including Carcharhinus brachyurus (East Asian subspecies), great white shark, basking shark (worldwide), and semi saw shark, whale sharks and sharp guitarfish and one species of ray are categorized into vulnerable species. Basking shark (the North Pacific population) belongs to endangered species and Hypoprion atripinnis (duskyfin shark) is classed into critically

\footnotetext{
${ }^{17}$ See Animal Welfare Regarded as a Major Course, (Aug. 7, 2013). Available at http://hope.huanqiu.com/domesticnews/2013-08/4216959.html.

${ }^{18}$ The lists of key aquatic wild animals under special protection (national) include whale shark, basking shark and great white shark; the lists of key aquatic wild animals under special protection (Guangdong) include whale shark and basking shark; the lists of key aquatic wild animals under special protection (Jiangsu) include banded houndshark.
} 
endangered species.

In addition, according to CITES and the State's related regulations, endangered animals listed in CITES I \& II are supervised as the China national first-level and second level protected animals. While whale shark, basking shark and great white shark are listed in CITES appendix II, they should be supervised as national second-level protected animals.

\section{Public InTEREST Litigation AND LEgisLATIVE PROPOSALS}

Under the existing legal frame in China, wildlife resources belong to the whole people, which have property attribute. From the start, animals did not have the same rights as the natural person. Although legal personality can be entitled (such as legal persons, other organizations etc.), if wild animals are endowed with legal personality in Chinese society, there will be legal obstacles. Even wild animals are endowed with legal personality, during the right exercise process still need a natural person to agent.

Of course we should notice that, to discuss wild animal rights is a kind of progress. Under the existing legal framework, it is feasible to suggest introducing and strengthening wildlife protection of public interest litigation system.

January 1, 2013, implementation of China's new Civil Procedural Law Article 55 provides that, "to pollute the environment, infringe upon the consumers' legitimate and interests, harm the social and public interests the law of authorities and relevant organizations can bring a suit to the people's court." 19 Thus, the scope of environmental damage, public interest litigation includes not only polluting the environment, infringing upon the consumers' legitimate and interests but harming the social and public interests. So the destruction of wildlife resources also belongs to this category destruction of the ecological environment. For the main proceedings, it can be carefully considered on the basis of stipulations in the "law authorities and relevant organizations".

On April 24, 2014, by the definition of Criminal Law judicial interpretation, consumption of illegal purchase of rare wild animals will be held criminally responsible, in serious cases, it shall be liable to imprisonment for more than a decade. If part of endangered shark specials is included in the lists of wildlife under special state protection, this provision will provide a strong guarantee to protect them. Since December 13, 2013, China has been revising the law on the protection of wildlife. At present, the first draft is in modification and argumentation, and the first trial will be

\footnotetext{
${ }^{19}$ See Civil Procedural Law of China, Article 55.
} 
hold by the NPC standing committee by the end of the year $2015 .{ }^{20}$

Meanwhile, we put forward legislative suggestions as follows:

(1) The shark should be included in the "list of national key protected wild animals", so the relevant laws and regulations can give a clear basis for enforcement; or introduced specifically for shark protection legislation, such as "special regulations to protect sharks", the protection and management of sharks should be clearly defined.

(2) To establishes the specialized agencies to supervise the shark fishing, recourse conservation. At the same time, we can gradually standardize the operation of shark fisheries system to ensure that shark stocks, to achieve sustainable fishing by issuing fishing license, setting up fishery resources reserves, controlling the fishing intensity and other measures.

(3) Do a good job in international performance, strictly implement the provisions of CITES and strengthen the supervision of shark fishing trade activities. According to the key state protective animals, we should manage, protect, conserve the whale sharks, basking sharks, great sharks, which are listed in the CITES Appendix, and utilized fishery resources reasonably.

(4) Strictly regulate the animal experiment which are carried out in the name of the scientific research; improve the system of using the tracking on the shark research; carry out supervision system and verifying by both the examining and approving before the experiment and the result after the experiment; advocate scientific research activities with human conscience and civilization; and object to slaughter and abuse of wild animals.

\section{CONCLUSION}

Although it has an extended history in China, consuming shark fins, which has been available exclusively to few wealthy families, is not the main part of the traditional catering culture. And from the prospective of nutrition, eating shark fins has no advantage. On the contrary, it may damage health as mercury and other heavy metal accumulated in shark fins may be much higher than that of other fishes. Over fishing, driven by shark fin consumption, not only leads to the shark species' extinction, but threats the balance of marine environment. In order to stop shark fin consumption, we need to utilize as much as we can get, including moral restriction, media pressure and legal policy, and make reforms step by step. We are delighted to see some progress that has been made. For instance, according to the

\footnotetext{
${ }^{20}$ See Revising the Law on the Protection of Wildlife, (Dec. 16, 2014). Available at http://politics.gmw.cn/2014-12/16/content_14183640.htm.
} 
latest report on shark fin consumption tendency issued by WildAid in Beijing on August, 2014, quantity and price of shark fins are both dropping. Over the past two years, the import of shark fins in Hong Kong region fell by nearly half. In the past two years, the suppliers in Guangzhou, where it is the trade center of shark fin, said sales fell by $82 \%$, prices fell by $47 \%$, wholesale prices fell by $57 \%$. Online survey of consumers shows that, $85 \%$ of people said they had not consumed shark fin dishes in the past three years. ${ }^{21}$ However, this does not mean the end of this fight. There is still a long way ahead of us. Legal protection is the most significant part. China needs to revise the law on the protection of wildlife, while taking a series of other supporting methods, like listing shark as one of national key protected wild animals.

\footnotetext{
${ }^{21}$ See Quantity and Price of Shark Fins both Drop, (Aug. 06, 2014). Available at http://news.xinhuanet.com/energy/2014-08/06/c_126837248.htm.
} 